\title{
Simple and Versatile Dynamic Model of Spherical Roller Bearing
}

\author{
Behnam Ghalamchi, Jussi Sopanen, and Aki Mikkola \\ Department of Mechanical Engineering, Lappeenranta University of Technology, P.O. Box 20, 53851 Lappeenranta, Finland
}

Correspondence should be addressed to Behnam Ghalamchi; behnam.ghalamchi@lut.fi

Received 7 February 2013; Accepted 21 August 2013

Academic Editor: Paolo Pennacchi

Copyright (C) 2013 Behnam Ghalamchi et al. This is an open access article distributed under the Creative Commons Attribution License, which permits unrestricted use, distribution, and reproduction in any medium, provided the original work is properly cited.

\begin{abstract}
Rolling element bearings are essential components of rotating machinery. The spherical roller bearing (SRB) is one variant witnessing increasing use because it is self-aligning and can support high loads. It is becoming increasingly important to understand how the SRB responds dynamically under a variety of conditions. This study introduces a computationally efficient, three-degree-offreedom, SRB model that was developed to predict the transient dynamic behaviors of a rotor-SRB system. In the model, bearing forces and deflections were calculated as a function of contact deformation and bearing geometry parameters according to the nonlinear Hertzian contact theory. The results reveal how some of the more important parameters, such as diametral clearance, the number of rollers, and osculation number, influence ultimate bearing performance. One pair of calculations looked at bearing displacement with respect to time for two separate arrangements of the caged side-by-side roller arrays, when they are aligned and when they are staggered. As theory suggests, significantly lower displacement variations were predicted for the staggered arrangement. Following model verification, a numerical simulation was carried out successfully for a full rotor-bearing system to demonstrate the application of this newly developed SRB model in a typical real world analysis.
\end{abstract}

\section{Introduction}

Bearings are one of the most important components in mechanical systems, and their reliable operation is necessary to ensure the safe and efficient operation of rotating machinery [1]. For this reason, a multipurpose dynamic roller bearing model capable of predicting the dynamic vibration responses of rotor-bearing systems is important. However, bearings introduce nonlinearities, often leading to unexpected behaviors, and these behaviors are sensitive to initial conditions. For rolling element bearings, the significant sources of nonlinearity are radial clearance between the rolling elements and raceways and the nonlinear restoring forces between the various curved surfaces in contact. A special type of nonlinearity is introduced to the system if the contact surfaces have distributed defects, such as waviness, or localized defects, such as inner or outer ring defects.

Goenka and Booker [2] extended the general applicability of the finite element method to include spherical roller bearings (SRBs). In their research, triangular finite elements with linear interpolation functions were used to model the lubricant film. Loading conditions for spherical roller bearings with elastohydrodynamic and hydrodynamic lubrication effects were analyzed by Kleckner and Pirvics [3]. They simulated the mechanical behavior of spherical roller bearings in isothermal conditions.

Creju et al. [4,5] improved the dynamic analysis of tapered roller bearings by improving integration of the differential equations that describe the dynamics of the rollers and bearing cage. Their study considered the effects of centrifugal forces and the gyroscopic moments of the rollers. The effects of correction parameters for roller generatrices in spherical roller bearings were discussed by Krzemiński-Freda and Warda [6]. They focused in their study on determining a proper ratio of osculation coefficients for both races to obtain self-stabilization of the barrel shaped roller and to minimize friction losses.

Olofsson and Björklund [7] performed 3D surface measurements and analysis on spherical roller thrust bearings that revealed the different wear mechanisms.

A theoretical model for estimating the stiffness coefficients of spherical roller bearings was developed by Royston and Basdogan [8] showing that coefficient values are complicated functions, dependent on radial and axial preloads. 
While this work is useful for qualitative analysis, it cannot deliver the dynamic insights needed for understanding the high performance machine systems.

Olofsson et al. [9] simulated the wear of boundary lubricated spherical roller thrust bearings. A wear model was developed in which the normal load distribution, tangential tractions, and sliding distances can be calculated to simulate the changes in surface profile due to wear. Taking into account internal geometry and preload impacts, Bercea et al. [10] applied a vector-and-matrix method to describe total elastic deflection between double-row bearing races. This study focused only on static analysis. It is not capable of delivering a detailed analysis of the complex dynamic behaviors of spherical roller bearing systems involving nonlinear interactions between rollers and inner/outer races.

Cao and Xiao [11, 12] established and applied a comprehensive spherical roller bearing model to provide quantitative performance analyses of SRBs. In addition to the vertical and horizontal displacements considered in previous investigations, the impacts of axial displacement and load were addressed by introducing degrees-of-freedom in the axial shaft direction. The point contacts between rollers and inner/outer races were considered. These bearing models have a large number of degrees-of-freedom since there is one degree-of-freedom (DOF) for each roller and an additional 3 to $5 \mathrm{DOFs}$ for the inner race. Its high complexity makes this bearing model unattractive for the analysis of complete rotorbearing systems. For example, a single gear-box can contain up to ten roller bearings.

The effect of centrifugal forces on lubricant supply layer thickness in the roller bearings was considered by van Zoelen et al. [13]. In particular, this model is used to predict lubricant layer thickness on the surface of the inner and outer raceways and each of the rollers. In this extended model, it is assumed that the lubricant layers for each of the roller raceway contacts are divided equally between the diverging surfaces.

Although a large number of ball bearing models exist, there has been little study of spherical roller bearing dynamics. For example, Harsha et al. [14, 15] studied the rolling element dynamics for certain imperfect configurations of single row deep-grooved ball bearings. The study revealed dynamic behaviors that are extremely sensitive to small variations in system parameters, such as the number of balls and the number of waves. A dynamic model of deep-grooved ball bearings was proposed by Sopanen and Mikkola $[16,17]$. They considered the effects of distributed defects such as surface waviness and inner and outer imperfections.

This paper introduces a new general purpose spherical roller bearing model developed to act as an interface element between a spinning rotor and its supporting structure. Spherical roller bearings experience point contact between the inner race, rolling element, and outer race in the no-load condition and elliptical contact when loaded. The modeling approach presented in this paper accounts for the loaded condition and has three degrees-of-freedom. Its simplifying assumptions make the model computationally efficient. It is accurate enough for an engineering analysis, since it can capture the most important dynamic properties of the bearing.
Model performance was demonstrated by comparing the results of two basic numerical simulations to the results obtained using both commercial bearing analysis software and the bearing radial deflection formula proposed by Gargiulo [18]. The simulations focused on the more important design parameters: diametral clearance, number of rollers, and osculation. A third numerical simulation of a full bearing system was performed to demonstrate the application of this new SRB model in a typical real world analysis.

\section{Dynamic Model of the Spherical Roller Bearing}

A spherical roller bearing consists of a number of parts, including a series of rollers, a cage, and the inner and outer raceways. Describing each component in detail can result in a simulation model with a large number of degrees-offreedom. Additionally, as with all radial rolling bearings, spherical roller bearings are designed with clearance. This clearance also increases the computational complexity of the system. However, bearing analysis computation should be efficient so it can be used to simulate the dynamics of complete machine systems. To improve the computational efficiency of the proposed spherical roller bearing model the following simplifications have been introduced.

(1) Cage movement is based on the geometric dimensions of the bearing; therefore, it is assumed that no slipping or sliding occurs between the components of the bearing and that all rollers move around the raceways with equal velocity.

(2) The inner raceway is assumed to be fixed rigidly to the shaft.

(3) There is no bending deformation of the raceways. Only nonlinear Hertzian contact deformations are considered in the area of contact between the rollers and raceways.

(4) The bearings are assumed to operate under isothermal conditions.

(5) Rollers are equally distributed around the inner race, and there is no interaction between them.

(6) The centrifugal forces acting on the rollers are neglected.

The bearing stiffness matrix and bearing force calculation routines are implemented according to the block diagrams shown in Figure 1. The bearing geometries, material properties and the displacements between the bearing rings are defined as inputs. For the stiffness matrix calculation routine, the external force on the bearing is given as an input. The bearing force calculation routine can be used as a stand-alone program or as part of a bearing stiffness matrix calculation routine in a multibody or rotor dynamic analysis code.

In the following sections, the theory behind the bearing force and bearing stiffness matrix calculation is explained in detail. 


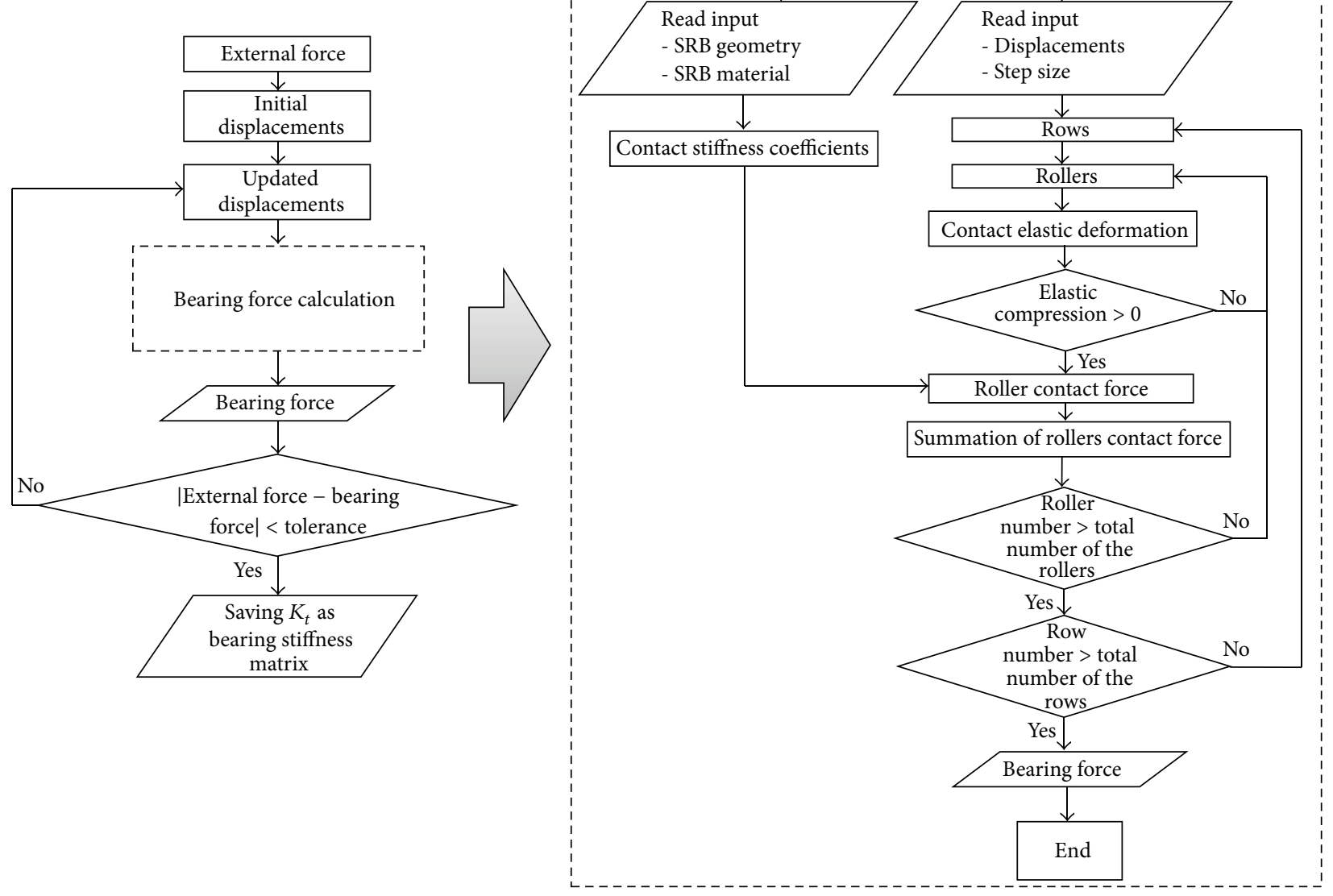

FIGURE 1: Block diagram for the bearing stiffness matrix and bearing force calculation.

2.1. Geometry of Contacting Elastic Solids. Two solids that have different radii of curvature in two directions ( $x$ and $y$ ) are in point contact when no load is applied to them. When the two solids are pressed together by a force $F$, the contact area is elliptical. For moderately loaded spherical roller bearings, the contact conjunction can be considered elliptical [3], as shown in Figure 2. The following analysis will assume that the curvature is positive for convex surfaces and negative for concave surfaces [19].

The geometry between two solids in contact $(A$ and $B)$ can be expressed in terms of the curvature sum $(R)$ and the curvature difference $\left(R_{d}\right)$ as follows $[20,21]$ :

$$
\begin{gathered}
\frac{1}{R}=\frac{1}{R_{x}}+\frac{1}{R_{y}}, \\
R_{d}=R\left(\frac{1}{R_{x}}-\frac{1}{R_{y}}\right) .
\end{gathered}
$$

The curvature sums in $x$ and $y$ are defined as follows:

$$
\frac{1}{R_{x}}=\frac{1}{r_{A x}}+\frac{1}{r_{B x}},
$$

$$
\frac{1}{R_{y}}=\frac{1}{r_{A y}}+\frac{1}{r_{B y}} .
$$

Variables $R_{x}$ and $R_{y}$ represent the effective radii of curvature in the principal $x$ - and $y$-planes. When the two solids have a normal load applied to them, the point expands to an ellipse with " $a_{e}$ " being a semimajor axis and " $b_{e}$ " being the semiminor axis. The elliptic parameter is defined as [19]

$$
k_{e}=\frac{a_{e}}{b_{e}} .
$$

The elliptic parameter can be defined as a function of the curvature difference $R_{d}$ and the elliptic integrals of the first $\xi$ and second $\zeta$ kinds as follows [21]:

$$
k_{e}=\left[\frac{2 \xi-\zeta\left(1+R_{d}\right)}{\zeta\left(1-R_{d}\right)}\right]^{1 / 2} .
$$




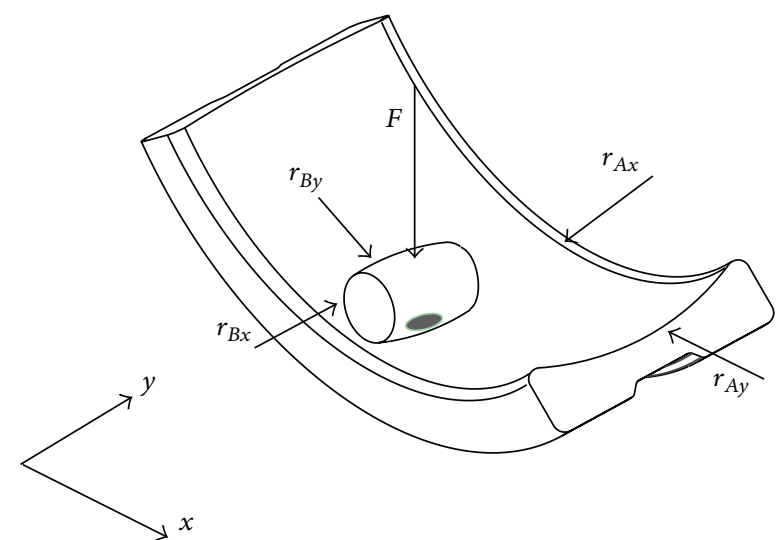

FIGURE 2: Elliptical contact conjunctions. $\zeta:$

The following (5) defines the first and second kinds $\xi$ and

$$
\begin{aligned}
& \xi=\int_{0}^{\pi / 2}\left[1-\left(1-\frac{1}{k^{2}}\right) \sin ^{2} \phi\right]^{-1 / 2} d \phi, \\
& \zeta=\int_{0}^{\pi / 2}\left[1-\left(1-\frac{1}{k^{2}}\right) \sin ^{2} \phi\right]^{1 / 2} d \phi .
\end{aligned}
$$

The angle $\phi$ is an auxiliary angle. Brewe and Hamrock [20] used numerical iteration and curve fitting techniques to find the following approximation formulas for the ellipticity parameter $k_{e}$ and the elliptical integrals of the first $\xi$ and second $\zeta$ kinds as follows:

$$
\begin{gathered}
k_{e}=1.0339\left(\frac{R_{y}}{R_{x}}\right)^{0.6360}, \\
\xi=1.0003+0.5968 \frac{R_{x}}{R_{y}}, \\
\zeta=1.5277+0.6023 \ln \left(\frac{R_{y}}{R_{x}}\right) .
\end{gathered}
$$

2.2. Geometry of Spherical Roller Bearing. The most important geometric dimensions of the spherical roller bearing are shown in Figure 3. Diametral clearance is the maximum diametral distance that one race can move freely. Osculation is defined as the ratio between the roller contour radius and the race contour radius as

$$
C=\frac{r_{r}}{r_{i, o}}
$$

Subscripts $r, i$, and $o$ refer to roller, inner race, and outer race, respectively. Perfect osculation is when $C$ is equal to 1 . In general, maximum contact pressure between the race and the roller decreases as osculation increases. Decreasing contact pressure reduces fatigue damage to the rolling surfaces; however, there is more frictional heating with increasing conformity. A reasonable value for osculation and one that can be used in the roller contour radius definition is 0.98 [1].

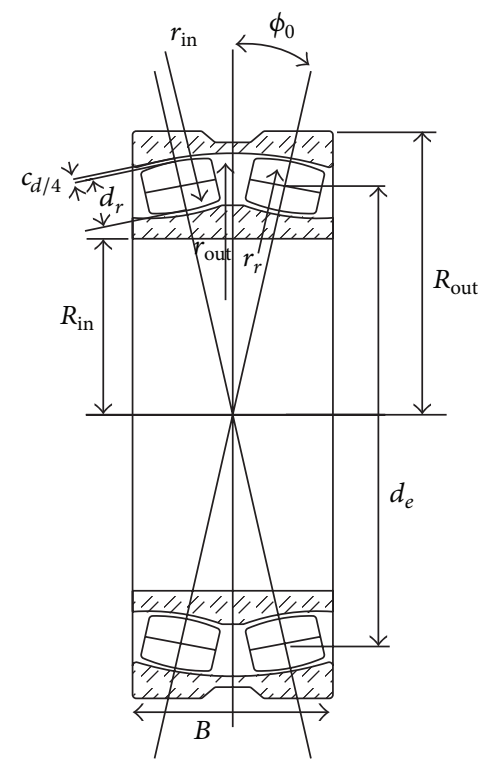

$R_{\text {in }}:$ bore radius

$R_{\text {out }}$ : outer radius

$r_{\text {out }}:$ outer raceway sphere radius

$d_{r}$ : roller diameter $d_{e}$ : bearing pitch diameter

$r_{r}:$ roller contour radius $c_{d}$ : diametral clearance

$r_{\text {in }}:$ inner raceway contour radius

$\phi_{0}$ : free contact angle

$B$ : bearing width

FIGURE 3: Dimension of spherical roller bearing.

Figure 4 illustrates the radii of curvature between roller, outer race, and inner race of an SRB.

The figure suggests that the radii of curvature for the roller-to-inner race contact area can be written as follows:

$$
\begin{gathered}
r_{A x}^{\text {in }}=\frac{d_{r}}{2}, \\
r_{A y}^{\text {in }}=r_{r}, \\
r_{B x}^{\text {in }}=\frac{d_{e}-d_{r} \cos \phi_{0}-\left(c_{d} / 2\right) \cos \phi_{0}}{2 \cos \phi_{0}}, \\
r_{B y}^{\text {in }}=-r_{\text {in }} .
\end{gathered}
$$

Similarly, the equations for the radii of curvature for roller-to-outer race contact can be written as

$$
\begin{gathered}
r_{A x}^{\text {out }}=\frac{d_{r}}{2} \\
r_{A y}^{\text {out }}=r_{r} \\
r_{B x}^{\text {out }}=-\frac{d_{e}+d_{r} \cos \phi_{0}+\left(c_{d} / 2\right) \cos \phi_{0}}{2 \cos \phi_{0}} \\
r_{B y}^{\text {out }}=-r_{\text {out }} .
\end{gathered}
$$

2.3. Contact Deformation in Spherical Roller Bearing. From the relative displacements between the inner and outer race, 

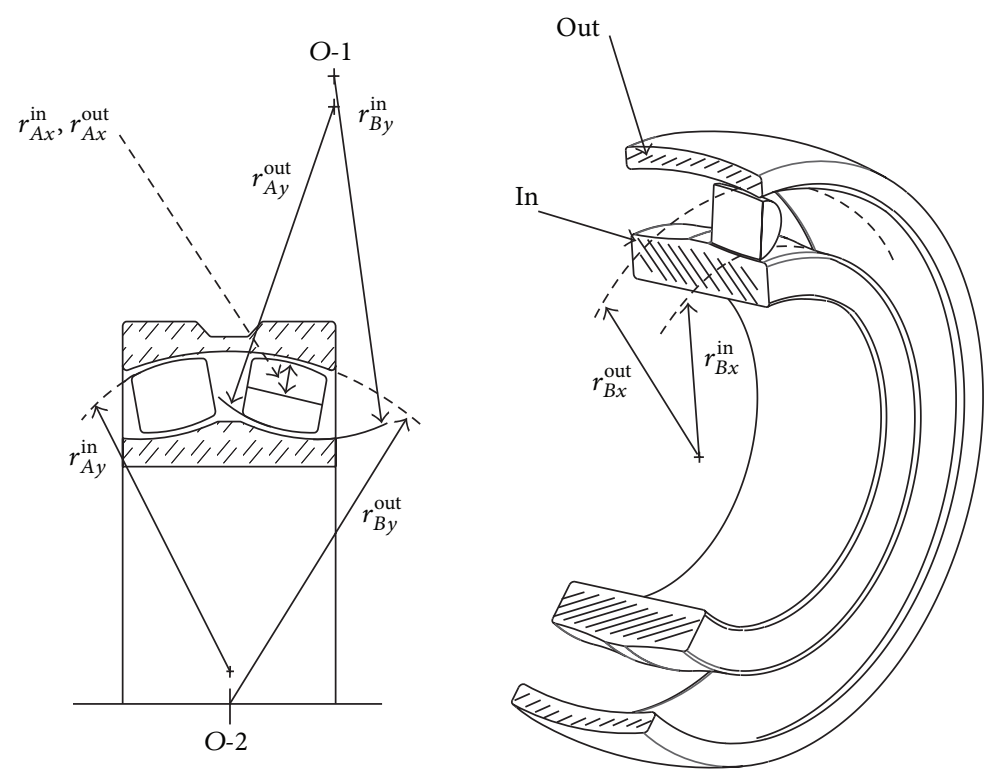

FiguRE 4: Radii of curvature between roller, outer race, and inner race.

the resultant elastic deformation can be determined of the $i$ th rolling element of the $j$ th row located at angle $\beta_{j}^{i}$. The initial distance $A_{0}$ between the inner and outer raceway curvature centers $(O-1, O-2)$ can be written, again based on Figure 4 drawing, as

$$
A_{0}=r_{B y}^{\text {out }}+r_{B y}^{\text {in }}-d_{r}-\frac{c_{d}}{2} .
$$

The corresponding loaded distance for roller $i$ in row $j$ can be written as follows:

$$
A\left(\beta_{j}^{i}\right)=\sqrt{\left(\delta_{z j}^{i}\right)^{2}+\left(\delta_{r j}^{i}\right)^{2}},
$$

where $\delta_{z j}^{i}$ and $\delta_{r j}^{i}$ are the displacements for roller $i$ in row $j$ in the axial and radial directions, respectively, which can be determined using these equations:

$$
\begin{gathered}
\delta_{z j}^{i}=A_{0} \sin \left(\phi_{0}\right)+e_{z}, \\
\delta_{r j}^{i}=A_{0} \cos \left(\phi_{0}\right)+e_{x} \cos \left(\beta_{j}^{i}\right)+e_{y} \sin \left(\beta_{j}^{i}\right) .
\end{gathered}
$$

The variables $e_{x}, e_{y}$, and $e_{z}$ represent displacements in the $x y z$-coordinate system, and $\beta_{j}^{i}$ is the attitude angle of roller $i$ in row $j$; see Figure 5 . The initial contact angle $\phi_{0}$ is negative for the 1st row and positive for the 2nd row of the bearing.

The distance between race surfaces along the common normal is given by

$$
d\left(\beta_{j}^{i}\right)=\left|r_{B y}^{\text {out }}\right|+\left|r_{B y}^{\text {in }}\right|-A\left(\beta_{j}^{i}\right) .
$$

Elastic compression becomes

$$
\delta_{\beta_{j}^{i}}=d_{r}-d\left(\beta_{j}^{i}\right) .
$$

And the loaded contact angle in each roller element can be defined as follows:

$$
\phi_{j}^{i}=\tan ^{-1}\left(\frac{\delta_{z j}^{i}}{\delta_{r j}^{i}}\right) .
$$

2.4. Elastic Deformation in Spherical Roller Bearing. In a single rolling element, total deflection is the sum of the contact deflections between the roller and the inner and outer races. The deflection between the roller and the race can be approximated as given by [19]

$$
\delta_{0}=\left(\frac{F}{K_{c}}\right)^{2 / 3} .
$$

The $F$ denotes normal load, and $K_{c}$ is the contact stiffness coefficient, which can be calculated using the elliptic integral and ellipticity parameter in this manner:

$$
k_{c}=\pi k_{e} E^{\prime} \sqrt{\frac{R \bar{\xi}}{4.5 \bar{\zeta}^{3}}} .
$$

The effective modulus of elasticity $E^{\prime}$ is defined as follows:

$$
\frac{1}{E^{\prime}}=\frac{1}{2}\left(\frac{1-v_{a}^{2}}{E_{a}}+\frac{1-v_{b}^{2}}{E_{b}}\right)
$$

$E$ and $v$ are the modulus of elasticity and Poisson's ratio of solids $a$ and $b$. The total stiffness coefficient for both inner and outer race contact areas can be expressed with the following equation:

$$
k_{c}^{\text {tot }}=\frac{1}{\left[\left(1 / k_{c}^{\text {in }}\right)^{2 / 3}+\left(1 / k_{c}^{\text {out }}\right)^{2 / 3}\right]^{3 / 2}} .
$$




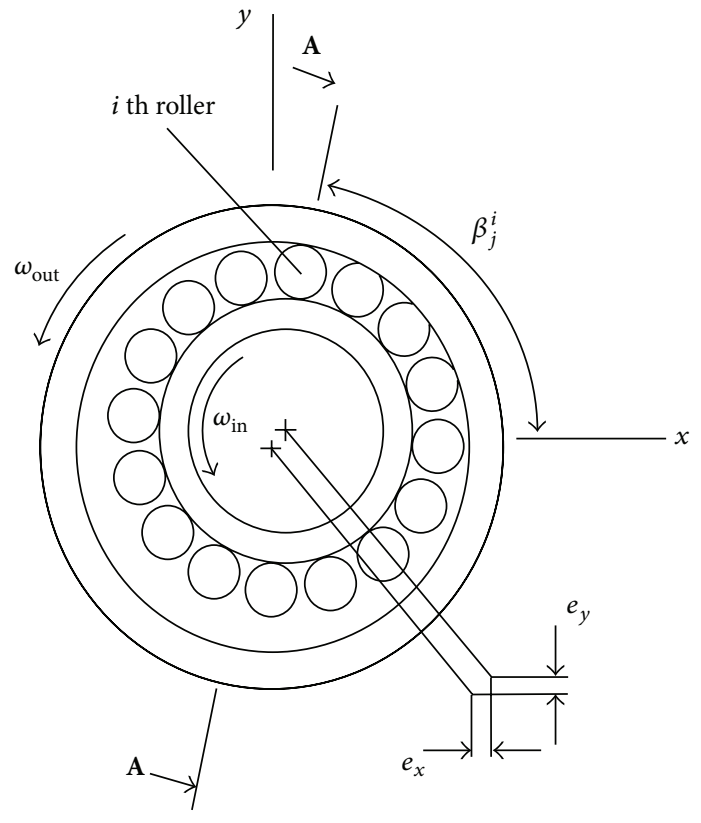

(a)

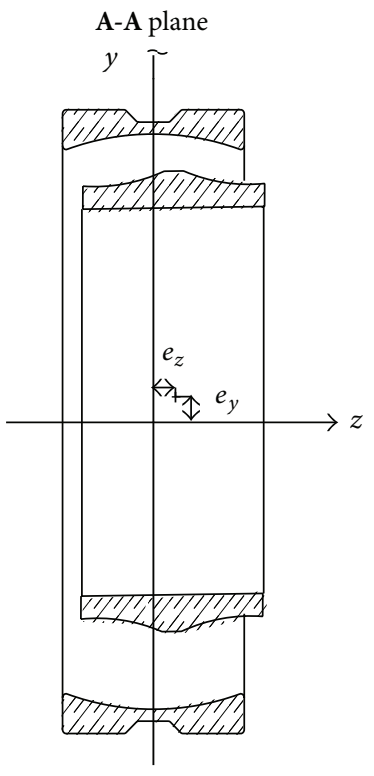

(b)

Figure 5: (a) Axial and (b) transverse cross-section in the A-A plane of spherical roller bearing.

According to (14) and (19), the contact force for roller $i$ in row $j$ can be calculated in this manner:

$$
F_{j}^{i}=k_{c}^{\mathrm{tot}}\left(\delta_{\beta_{j}^{i}}\right)^{1.5} \text {. }
$$

Finally, the total bearing force components acting upon the shaft in the $x, y$, and $z$ directions can be written according to these 3 equations:

$$
\begin{gathered}
F_{x}=-\sum_{j=1}^{2} \sum_{i=1}^{N} F_{j}^{i} \cos \phi_{j}^{i} \cos \beta_{j}^{i}, \\
F_{y}=-\sum_{j=1}^{2} \sum_{i=1}^{N} F_{j}^{i} \cos \phi_{j}^{i} \sin \beta_{j}^{i}, \\
F_{z}=-\sum_{j=1}^{2} \sum_{i=1}^{N} F_{j}^{i} \sin \phi_{j}^{i} .
\end{gathered}
$$

The variable $N$ is the number of rolling elements in each row. In (21), only positive values of the contact force $F_{j}^{i}$ are taken into account, and $F_{j}^{i}=0$ for the negative values.

2.5. Calculating the Stiffness Matrix of an SRB. Since it has a significant effect in the static and dynamic analyses of rotating mechanical systems, an accurate estimation of the SRB stiffness matrix is needed. According to (21), for a known given load, the displacements of bearing $\mathbf{e}$ (with components $e_{x}, e_{y}$, and $e_{z}$ ) are calculated using the Newton-Raphson iteration procedure as follows:

$$
\mathbf{e}^{(n+1)}=\mathbf{e}^{(n)}-\left(\mathbf{K}_{T}^{(n)}\right)^{-1} \mathbf{Q}^{(n)} .
$$

The displacement values can be calculated at step $n+1$. In (22), $\mathbf{K}_{T}^{(n)}$ is the tangent stiffness matrix, and vector $\mathbf{Q}^{(n)}$ includes the bearing forces and external forces at iteration step $n$ as follows:

$$
\mathbf{Q}^{(n)}=\mathbf{Q}_{b}^{(n)}-\mathbf{Q}_{\mathrm{ex}}^{(n)} .
$$

The tangent stiffness matrix can be written as

$$
\mathbf{K}_{T}^{(n)}=\frac{\partial \mathbf{Q}^{(n)}}{\partial \mathbf{e}^{(n)}} .
$$

In this calculation process, the convergence criterion for the iteration is defined as follows:

$$
|\mathbf{Q}|<0.001 \cdot\left|\mathbf{Q}_{\mathrm{ex}}\right| .
$$

Finally, the tangent stiffness matrix, which is obtained from the last iteration step, is chosen as a bearing stiffness matrix.

\section{Single Bearing Numerical Simulations}

This study introduces a computationally efficient, threedegree-of-freedom, SRB model that was developed to predict the transient dynamic behaviors of a rotor-SRB system. To verify the new bearing model, a series of verifying numerical calculations were carried out for a single SRB subjected to a simple radial load. The SRB modeled was a double-row spherical roller bearing (FAG 21322-E1-TVPB) with 16 roller elements in each row. Table 1 gives the relevant dimensions and parameters of the roller bearing, which were used to define the model. All numerical calculations were performed using MATLAB-2011b. Some of the MATLAB results were 
TABLE 1: Dimensions and parameters of the spherical roller bearing.

\begin{tabular}{lccc}
\hline Free contact angle & $\varphi_{0}$ & 7.92 & degree \\
Roller diameter & $d_{r}$ & 29 & $\mathrm{~mm}$ \\
Inner raceway contour radius & $r_{i}$ & 106.61 & $\mathrm{~mm}$ \\
Outer raceway contour radius & $r_{o}$ & 106.61 & $\mathrm{~mm}$ \\
Roller contour radius & $r_{r}$ & 103.95 & $\mathrm{~mm}$ \\
Bearing width & $B$ & 50 & $\mathrm{~mm}$ \\
Clearance & $c_{d}$ & 41 & $\mu \mathrm{m}$ \\
Pitch diameter & $d_{e}$ & 175 & $\mathrm{~mm}$ \\
Number of rows & $n_{z}$ & 2 & - \\
Number of rolling elements in one row & $N$ & 16 & - \\
Modulus of elasticity & $E$ & 206 & $\mathrm{GPa}$ \\
Poisson's ratio & $v$ & 0.3 & - \\
\hline
\end{tabular}

compared to results obtained by applying the formula for the spherical roller bearing radial deflection (Gargiulo [18]) and the commercial bearing analysis software BearinX provided by the Schaeffler Group.

The model verification analysis series comprised six sets of MATLAB numerical calculations, each focused on a specific area of behavior. In the first set, roller contact forces were calculated for four levels of radial load. The second set explored the relationship between bearing displacement and load. A third set of calculations established how SRB elastic deformation changes with load as a function of diametral clearance. The effect of osculation number on bearing displacement for different levels of radial loading was the area of focus of the fourth set of calculations. The fifth set looked at changes in displacement as a function of radial load and the number of bearing rollers. Finally, the last pair of verification calculations looked at bearing displacement with respect to time for two separate arrangements of the caged side-by-side roller arrays, when they are aligned and when they are staggered.

3.1. Single Bearing Load Analysis: Contact Forces. The first set of calculations were performed to verify that the newly developed SRB model would simulate correctly how roller contact forces change with increasing load. Figure 6 shows the calculated contact force distribution for radial loads in the $y$ direction of $4,6,8$, and $10 \mathrm{kN}$. The figure demonstrates, as theory predicts, that at the input diametral clearance of $c_{d}=41$, fewer rollers support the lowest applied radial load, and as the load increases, the number of supporting rollers increases.

\subsection{Single Bearing Analysis: Elastic Deformation, Clearance,} and Load. The second set of calculations explored the relationship between bearing displacement and load. Figure 7 illustrates the predicted relationship between applied radial force and bearing displacement and show that displacement increases with the increasing load. This eccentric displacement of the rotating bearing centers is a result of bearing radial clearance $\left(c_{d}=41\right)$ and the elastic deformations occurring at the regions of roller-to-race contact. In Figure 7 , the red curve shows the behavior predicted by the BearinX commercial bearing software, and the black one shows the behavior predicted by the Gargiulo [18] formula for the spherical roller bearing radial deflection.

3.3. Single Bearing Analysis: Elastic Deformation, Clearance, and Load. The third set of calculations established how SRB elastic deformation changes with load as a function of diametral clearance $c_{d}$ Figure 8 . Figure 7 shows elastic deformation and radial loading force plotted for four different values of clearance. The simulations demonstrate that elastic deformation is not affected significantly by changes in $c_{d}$. This conclusion is supported by the BearinX prediction and the Gargiulo bearing radial deflection estimation. Although elastic deformation seems to be insensitive to changes in $c_{d}$, diametral clearance does affect displacement between the bearing races as expected.

3.4. Single Bearing Analysis: Osculation Number, Displacement, and Load. The effect of osculation number on displacement for different levels of radial loading was investigated with the fourth set of calculations. Figure 9 shows a family of displacement-to-load curves representing four different values for osculation number. The prediction reveals that osculation significantly affects bearing stiffness. An osculation number value of $C=0.96$ seems to correspond to the reference solution obtained using the BearinX software.

3.5. Single Bearing Analysis: Number of Rollers, Displacement, and Load. The fifth set of verification calculations looked at how displacement changes with radial load and the number of bearing rollers. The results are presented by Figure 10. They indicate that SRB load carrying capacity increases with its number of rolling elements. In this case, the BearinX software predicts slightly higher displacement values.

3.6. Single Bearing Analysis: Angular Alignment of Side-bySide Roller Arrays. The final set of verification calculations looked at bearing displacement with respect to time for two separate arrangements of the caged side-by-side roller arrays, when they are aligned and when they are staggered as Figure 11(a) illustrates. On the left of the figure, the Type A arrangement shows the twin roller arrays in alignment. On the right, Type B shows an $11.25^{\circ}$ angular offset between them. For this pair of calculations, an external force of $F_{y}=$ $-2000 \mathrm{~N}$ and an angular shaft velocity of $\omega_{\text {in }}=100 \mathrm{rad} / \mathrm{s}$ were applied. The outer bearing races were fixed, that is to say, $\omega_{\text {out }}=0$. Figure 11(b) plots the calculated $y$ displacements as a function of time assuming pure rolling motion between the bearing rollers and inner and outer raceways.

The Type A bearing shows a varying compliance (VC) vibration at a frequency of $123.6 \mathrm{~Hz}$. This is equal to the roller-pass-outer-ring frequency of the bearing. As expected, bearing Type B vibrates at twice the roller-pass-outer-ring frequency. In the Type A bearing, the displacement variation due to the $\mathrm{VC}$ effect is $0.34 \%$. In contrast, the displacement variation is $0.05 \%$ for the Type B bearing. The $11.25^{\circ}$ angular shift between the roller arrays seems to reduce the VC effect significantly. 


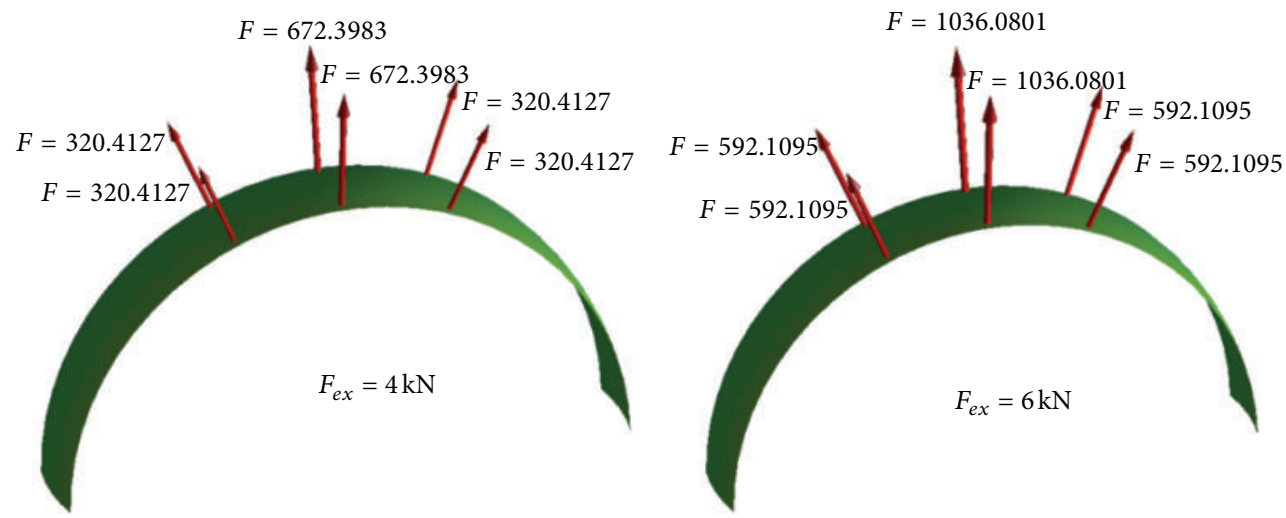

(a)

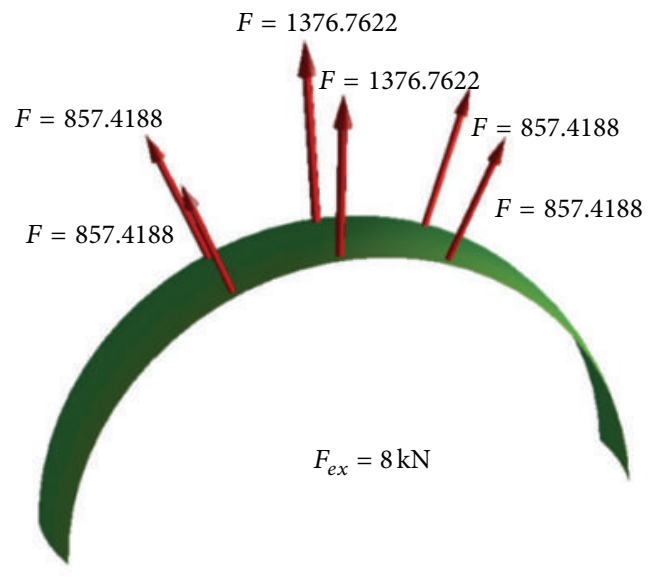

(c)

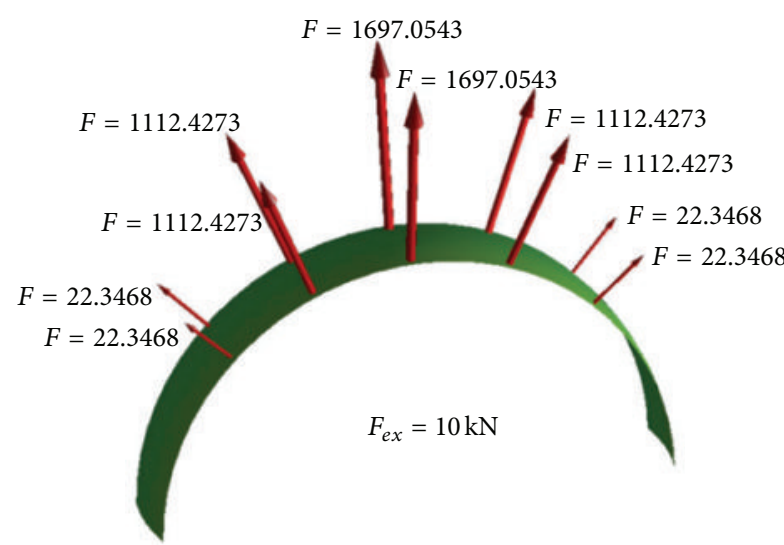

(d)

FIGURE 6: Contact forces of the rolling elements in case of different radial loads. The shaded surface represents the spherical surface of the outer race.

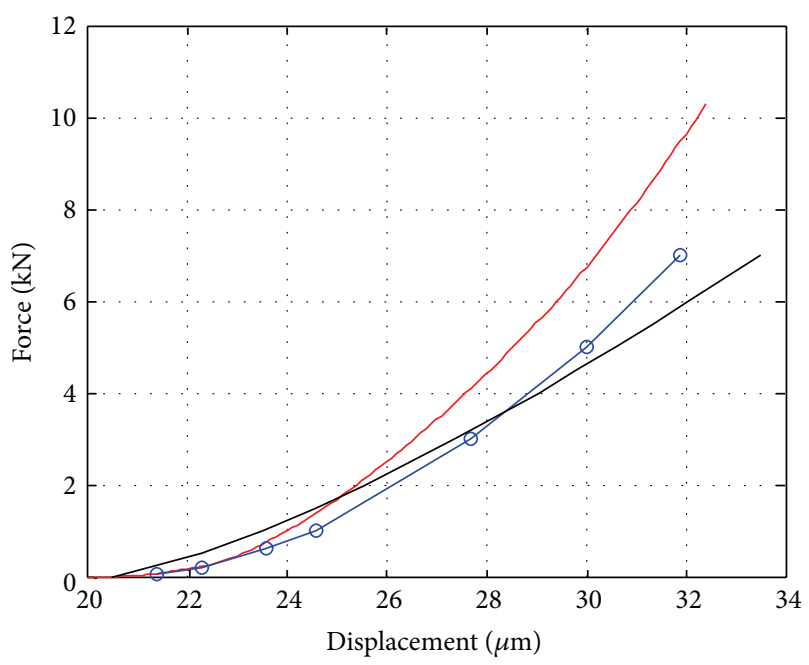

- SRB, Table 1 parameters

$\rightarrow$ BearinX

— Gargiulo (1980)

FIGURE 7: Radial force with respect to displacement.

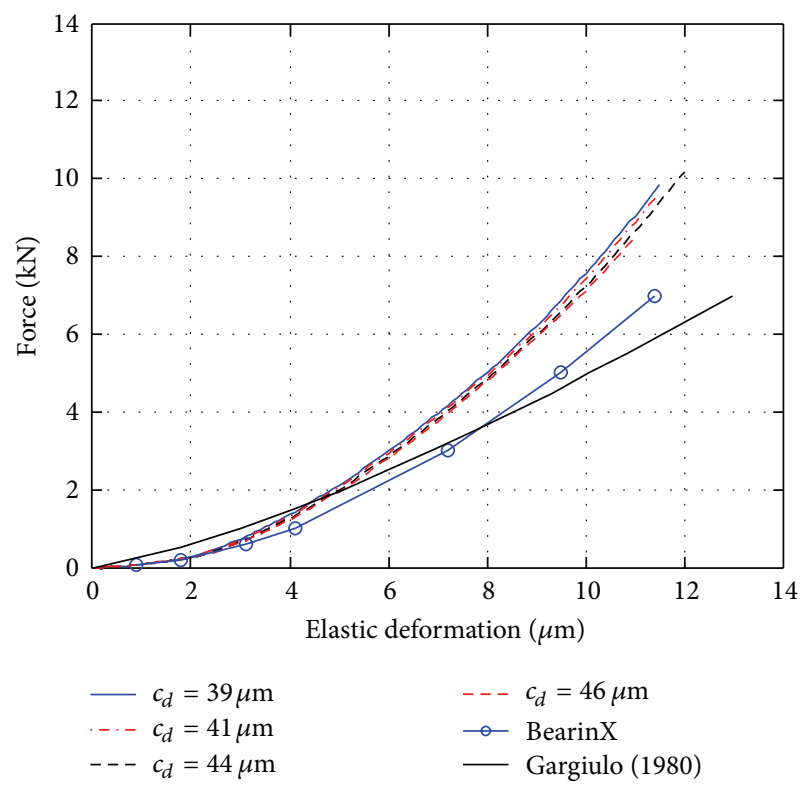

FIGURE 8: Effect of clearance on elastic deformation of the bearing. In this case, the elastic deformation is calculated by $e_{y}-\left(c_{d} / 2\right)$. 


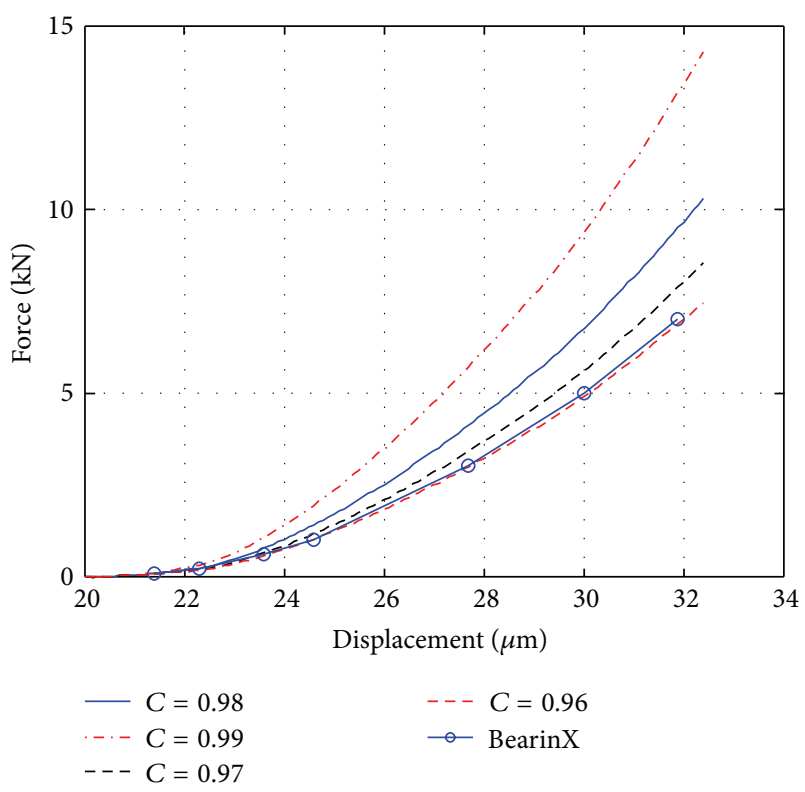

FIGURE 9: Effect of osculation number on radial force-displacement relationship.

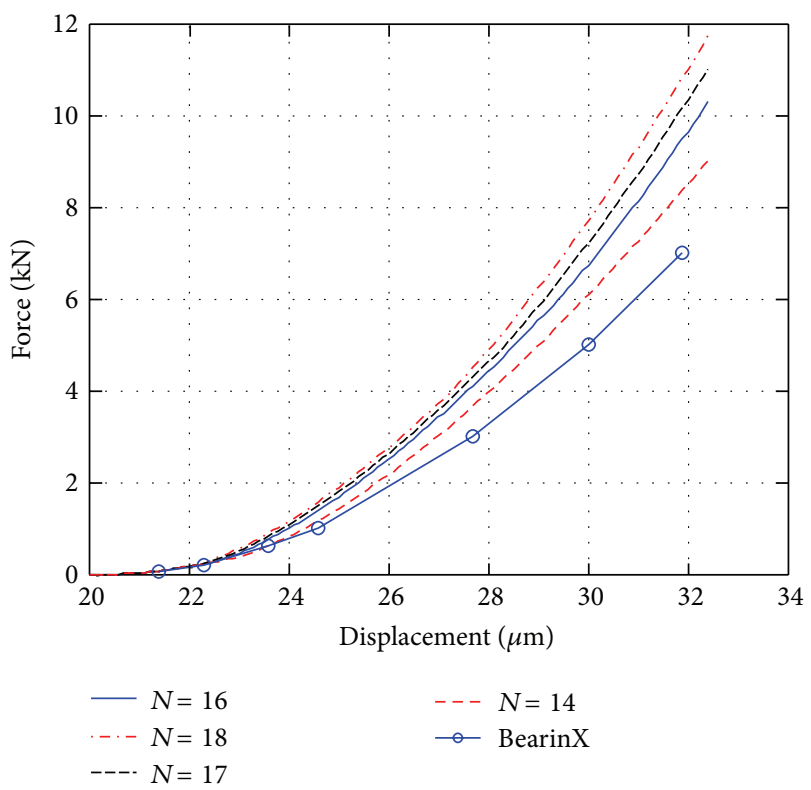

FIGURE 10: Effect of the number of rollers on radial force-displacement relationship.

\section{Dynamic Modeling a Rigid Rotor with Two Spherical Roller Bearings}

To demonstrate the application of the newly developed SRB model in a typical real world analysis, a numerical simulation was carried out of a full rotor-bearing system comprising a rigid rotor supported by SRBs on either end of the rotor axle. The rotor-bearing system, shown in Figure 12, can be described with eight degrees-of-freedom where the fourdegree-of-freedom are defined for both bearings housing
TABLE 2: Dimensions of the rigid rotor.

\begin{tabular}{lccc}
\hline Length & $L$ & 500 & $\mathrm{~mm}$ \\
Distance from center of rotor to bearing $A$ & $d_{A}$ & 225 & $\mathrm{~mm}$ \\
Distance from center of rotor to bearing $B$ & $d_{B}$ & 225 & $\mathrm{~mm}$ \\
End part diameter & $d_{2}$ & 110 & $\mathrm{~mm}$ \\
Middle part diameter & $d_{1}$ & 130 & $\mathrm{~mm}$ \\
Density & $\rho$ & 7850 & $\mathrm{~kg} / \mathrm{m}^{3}$ \\
Mass of rotor & $m_{R}$ & 49.138 & $\mathrm{~kg}$ \\
Transverse moments of inertia & $I_{x}=I_{y}$ & 0.9846 & $\mathrm{kgm}^{2}$ \\
Polar moment of inertia & $I_{z}$ & 0.0993 & $\mathrm{kgm}^{2}$ \\
\hline
\end{tabular}

displacements in the $x$ and $y$ directions and the next four-degree-of-freedom for rotor displacements that may be selected in many ways. One possibility is to use the center of mass translations in the $x$ and $y$ directions and the two rotations about those axes. Another possibility, which was selected for this work, is to use the translational coordinates of two bearing locations as the system's degree-of-freedom.

The bearing housings were connected to ground using linear spring-dampers, whose stiffness and damping coefficients are $K_{s}$ and $C_{s}$, respectively. The angular velocity of the rotor about the $z$-axis was assumed constant. Table 2 lists the dimensions and mass properties for the modeled rotor-SRB system.

Applying Newton's second law of motion, the movement of the rotor-SRB system can be expressed as follows:

$$
\mathbf{M} \ddot{\mathbf{q}}(t)+(\mathbf{C}+\Omega \mathbf{G}) \dot{\mathbf{q}}(t)+\mathbf{K q}(t)=\mathbf{F}(t),
$$

where $\mathbf{M}$ is mass matrix, $\mathbf{q}$ is the displacement vector, $\mathbf{C}$ is the damping matrix, $\Omega$ is rotation speed, $\mathbf{G}$ is the gyroscopic matrix, $\mathbf{K}$ is the stiffness matrix, and $\mathbf{F}$ is a vector of forces. For a rigid rotor, the effect of internal damping can be neglected, so it should be equal to zero, that is, $\mathbf{C}=\mathbf{0}$. Therefore, the equation of motion of rigid rotor in center of mass coordinates can be written as

$$
\mathbf{M}_{R c} \ddot{\mathbf{q}}_{R c}+\Omega \mathbf{G}_{R c} \dot{\mathbf{q}}_{R c}=\mathbf{F}_{R c},
$$

where $\mathbf{q}_{R c}=\left[\begin{array}{llll}x & y & \beta_{x} & \beta_{y}\end{array}\right]^{T}$, showing the transversal and tilting motions of the rotor in the $x$ and $y$ directions, and subscripts $R$ and $c$, respectively, refer to the rotor and center of mass of the rotor. Equation (28), which follows, presents the mass matrix $\mathbf{M}_{R c}$, the gyroscopic matrix $\mathbf{G}_{R c}$, and the force vector $\mathbf{F}_{R c}$ in center of gravity coordinates:

$$
\begin{gathered}
\mathbf{M}_{R c}=\left[\begin{array}{cccc}
m_{R} & 0 & 0 & 0 \\
0 & m_{R} & 0 & 0 \\
0 & 0 & I_{x} & 0 \\
0 & 0 & 0 & I_{y}
\end{array}\right], \\
\mathbf{G}_{R c}=\left[\begin{array}{cccc}
0 & 0 & 0 & 0 \\
0 & 0 & 0 & 0 \\
0 & 0 & 0 & 1 \\
0 & 0 & -1 & 0
\end{array}\right] I_{z}, \quad \mathbf{F}_{R c}=\left[\begin{array}{c}
F_{x} \\
F_{y} \\
\Theta_{x} \\
\Theta_{y}
\end{array}\right] .
\end{gathered}
$$

In (28), $m_{R}$ is the rotor mass, $I_{x}$ and $I_{y}$ are the transversal moments of inertia about the $x$ - and $y$-axes, respectively, 


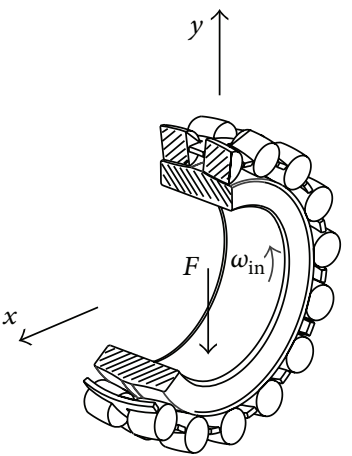

Both sides at the same level Type A

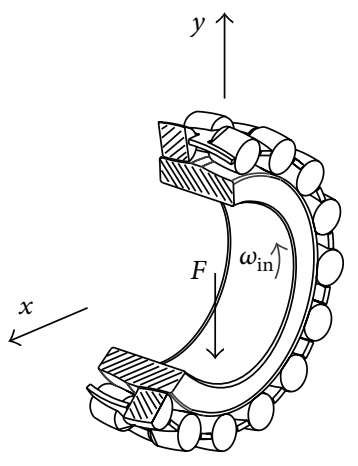

One side shifted equal to $11.25 \mathrm{deg}$ Type B

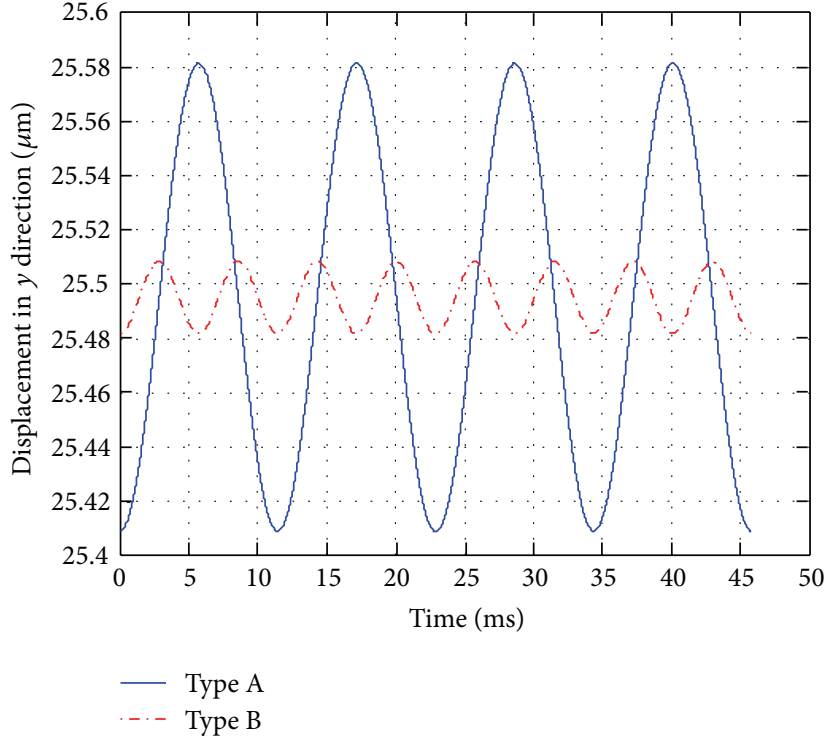

(b)

FIGURE 11: Effect of roller position on bearing force.

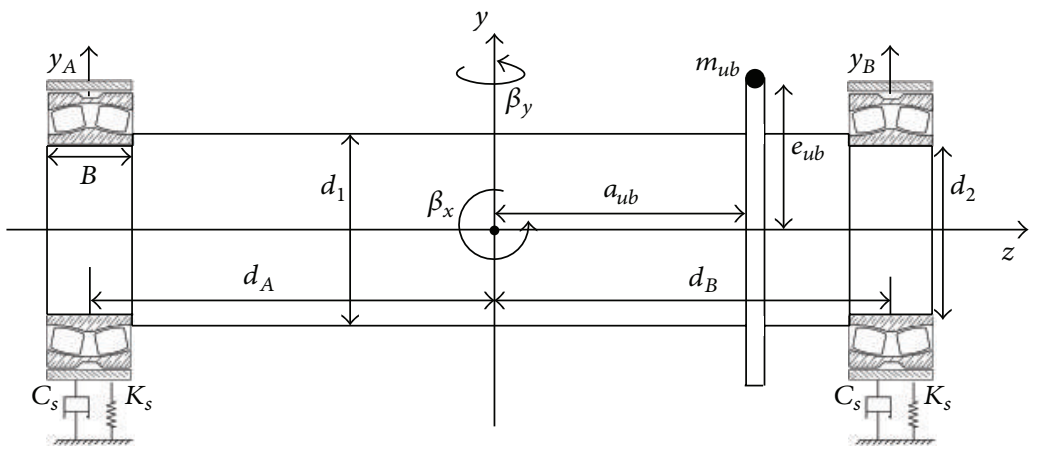

FIGURE 12: Rigid rotor supported with two spherical roller bearings.

and $I_{z}$ is the polar moment of inertia about the $z$-axis. $F$ and $\Theta$ denote force and moments on their axes. The rotor is assumed to be axisymmetric, so $I_{x}=I_{y}$. The equation of motion of rigid rotor in bearing coordinates is as follows:

$$
\mathbf{M}_{R b} \ddot{\mathbf{q}}_{R b}+\Omega \mathbf{G}_{R b} \dot{\mathbf{q}}_{R b}=\mathbf{F}_{R} .
$$

Subscript $b$ refers to the bearings. In bearing coordinates, $\mathbf{q}_{R b}=\left[\begin{array}{llll}x_{A} & y_{A} & x_{A} & y_{B}\end{array}\right]^{T}$ showing the rotor displacements at the SRBs in positions $A$ and $B$ in the $x$ and $y$ directions. $\mathbf{M}_{R b}$ and $\mathbf{G}_{R b}$ can be calculated as

$$
\mathbf{M}_{R b}=\mathbf{T}_{2}^{T} \mathbf{M}_{R c} \mathbf{T}_{2}, \quad \mathbf{G}_{R b}=\mathbf{T}_{2}^{T} \mathbf{G}_{R c} \mathbf{T}_{2},
$$

where $\mathbf{T}_{2}=\mathbf{T}_{1}^{-T}$. Transformation matrix $\mathbf{T}_{1}$ can be defined as follows:

$$
\mathbf{T}_{1}=\left[\begin{array}{cccc}
1 & 0 & 1 & 0 \\
0 & 1 & 0 & 1 \\
0 & -d_{A} & 0 & d_{B} \\
-d_{A} & 0 & d_{B} & 0
\end{array}\right]
$$

In (29), $\mathbf{F}_{R}$ includes the external forces $\left(\mathbf{F}_{\text {ex }}\right)$, the bearing forces $\left(\mathbf{F}_{b}\right)$, calculated from (21), the gravity forces for the rigid rotor $\left(\mathbf{F}_{g}\right)$, and the unbalance forces as shown by (32) and (33).

$$
\mathbf{F}_{R}=\mathbf{F}_{\mathrm{ex}}+\mathbf{F}_{b}+\mathbf{F}_{g}+\mathbf{F}_{\mathrm{ub}}
$$

In this particular case, the individual force components can be written with these equation:

$$
\mathbf{F}_{\mathrm{ex}}=\left[\begin{array}{c}
0 \\
-250 \\
0 \\
-250
\end{array}\right], \quad \mathbf{F}_{b}=\left[\begin{array}{c}
F_{x}^{A} \\
F_{y}^{A} \\
F_{x}^{B} \\
F_{y}^{B}
\end{array}\right]
$$


TABLE 3: Unbalance mass parameters of the rotor and support properties.

\begin{tabular}{lccc}
\hline Unbalance mass & $m_{\mathrm{ub}}$ & 0.005 & $\mathrm{~kg}$ \\
Eccentricity of the unbalance mass & $e_{\mathrm{ub}}$ & 0.1 & $\mathrm{~m}$ \\
Unbalance distance to center of mass of rotor & $a_{\mathrm{ub}}$ & 0.12 & $\mathrm{~m}$ \\
Phase angle of the unbalance mass & $\theta$ & 0 & $\mathrm{rad}$ \\
\hline
\end{tabular}

TABLE 4: The properties of the supporting structure.

\begin{tabular}{llcc}
\hline Bearing mass & $m_{s}$ & 11 & $\mathrm{~kg}$ \\
Support stiffness & $K_{s}$ & $1 \cdot 10^{7}$ & $\mathrm{~N} / \mathrm{m}$ \\
Support damper & $C_{s}$ & $5 \cdot 10^{3}$ & $\mathrm{Ns} / \mathrm{m}$ \\
\hline
\end{tabular}

$$
\mathbf{F}_{g}=\left[\begin{array}{c}
0 \\
-\frac{m_{r}}{2} g \\
0 \\
-\frac{m_{r}}{2} g
\end{array}\right], \quad \mathbf{F}_{\mathrm{ub}}=m_{\mathrm{ub}} e_{\mathrm{ub}} \Omega^{2}\left[\begin{array}{c}
\cos (\Omega t+\theta) L_{\mathrm{ub}} \\
\sin (\Omega t+\theta) L_{\mathrm{ub}} \\
\cos (\Omega t+\theta) R_{\mathrm{ub}} \\
\sin (\Omega t+\theta) R_{\mathrm{ub}}
\end{array}\right],
$$

where $m_{\mathrm{ub}}$ and $e_{\mathrm{ub}}$ are the mass and eccentricity and $\theta$ is the phase angle of the unbalanced mass, which is assumed zero. $L_{\mathrm{ub}}$ and $R_{\mathrm{ub}}$ are calculated as follows:

$$
L_{\mathrm{ub}}=\frac{d_{B}-a_{\mathrm{ub}}}{d_{B}+d_{A}}, \quad R_{\mathrm{ub}}=\frac{d_{A}+a_{\mathrm{ub}}}{d_{B}+d_{A}} .
$$

The unbalance mass parameters used in the rigid rotor model and the properties of the supporting structure are listed in Table 3.

For the bearing housing, the equation of motion also can be written as

$$
\mathbf{M}_{S} \ddot{\mathbf{q}}_{S}+\mathbf{C}_{S} \dot{\mathbf{q}}_{S}+\mathbf{K}_{S} \mathbf{q}_{S}=0
$$

where subscript $S$ refers to the supports and $\mathbf{q}_{S}=$ $\left[\begin{array}{llll}x_{S A} & y_{S A} & x_{S B} & y_{S B}\end{array}\right]^{T}$, showing the displacements of the bearings housing in the $x$ and $y$ directions. The mass matrix $\mathbf{M}_{S}$, the damper matrix $\mathbf{C}_{S}$, and the stiffness matrix $\mathbf{K}_{S}$ are presented as follows:

$$
\mathbf{M}_{S}=m_{S} \cdot \mathbf{I}_{4}, \quad \mathbf{C}_{S}=C_{S} \cdot \mathbf{I}_{4}, \quad \mathbf{K}_{S}=K_{S} \cdot \mathbf{I}_{4},
$$

where $\mathbf{I}_{4}$ is a $4 \times 4$ identity matrix and the properties of the supporting structure are listed in Table 4.

Finally, for the whole rotor-SRB system, the assembly matrix according to (29) and (35) can be written as follows:

$$
\begin{aligned}
& {\left[\begin{array}{cc}
\mathbf{M}_{R b} & 0 \\
0 & \mathbf{M}_{S}
\end{array}\right]\left[\begin{array}{l}
\ddot{\mathbf{q}}_{R b} \\
\ddot{\mathbf{q}}_{S}
\end{array}\right]+\left[\begin{array}{cc}
\Omega \mathbf{G}_{R b} & 0 \\
0 & \mathbf{C}_{S}
\end{array}\right]\left[\begin{array}{l}
\dot{\mathbf{q}}_{R b} \\
\dot{\mathbf{q}}_{S}
\end{array}\right]} \\
& +\left[\begin{array}{cc}
0 & 0 \\
0 & \mathbf{K}_{S}
\end{array}\right]\left[\begin{array}{l}
\mathbf{q}_{R b} \\
\mathbf{q}_{S}
\end{array}\right]=\left[\begin{array}{l}
\mathbf{F}_{R} \\
\mathbf{F}_{S}
\end{array}\right] .
\end{aligned}
$$

Using MATLAB-2011b, the dynamics of the rigid rotor and two SRBs were solved for rotation speed of $3000 \mathrm{rpm}$.
The differential equations of motion (37) were solved using an ode 45 time integrator scheme. Figure 13 shows the predicted horizontal and vertical translational rotor displacements at the $A$ and $B$ spherical roller bearing locations as a function of time. After a brief initial transient vibration, the rotor settles into steady-state harmonic vibration as a result of unbalanced forces. The rotor axis deflects in an elliptical orbit. Because of the positioning of the unbalanced load, the deflections for SRB $A$ are greater than those for SRB B. Figure 14 illustrates the orbital motion of the rotor axis.

Figures 13 and 14 show that total rotor displacement in the $y$ direction is about $84 \mu \mathrm{m}$ on average. Much of this displacement is due to elastic compression of the support springs. Theory predicts a value for support compression of about $60 \mu \mathrm{m}$. The additional $20 \mu \mathrm{m}$ displacement is bearing clearance. Therefore, the elastic compression of the SRB structure must be only a few micrometers in this case. However, the elliptical orbit of rotor axis displacement (Figure 14) shows greater displacement in the $x$-axis direction than in the $y$-axis direction, which implies differences in bearing stiffness. This difference is the result of bearing clearance, which is taken up in the $y$-axis as the $y$-direction radial load acts on the bearing and not taken up in the $x$-axis direction.

\section{Conclusion}

This study introduces a comprehensive and computationally efficient, three-degree-of-freedom, SRB model that was developed to predict the transient dynamic behaviors of a rotor-SRB system. The new SRB model can be used as an interface element between a rotor and its supporting structure in an analysis of rotor dynamics. The model is simple and useable for either steady-state or transient analyses. It takes into account the influences of roller angular position on bearing contact forces.

To verify the new bearing model, a series of verifying numerical calculations were carried out for a single SRB subjected to a simple radial load. Physical parameters such as contact force, bearing displacement, elastic deformation, diametral clearance, osculation number, and the number and arrangement of bearing rollers were examined to verify the model. The verification calculations supported or revealed the following.

(i) As theory predicts, roller contact forces change with increasing load. Fewer rollers support lower applied radial loads, and more rollers come into play as load increases.

(ii) Bearing displacement increases with increasing load.

(iii) Elastic deformation is not affected significantly by changes in $c_{d}$. Although elastic deformation seems to be insensitive to changes in $c_{d}$, diametral clearance does affect displacement between the bearing races.

(iv) Osculation significantly affects bearing stiffness, and the force and displacement responses are heavily dependent on bearing clearance and osculation number. These parameters must be considered for an accurate assessment of system performance. 


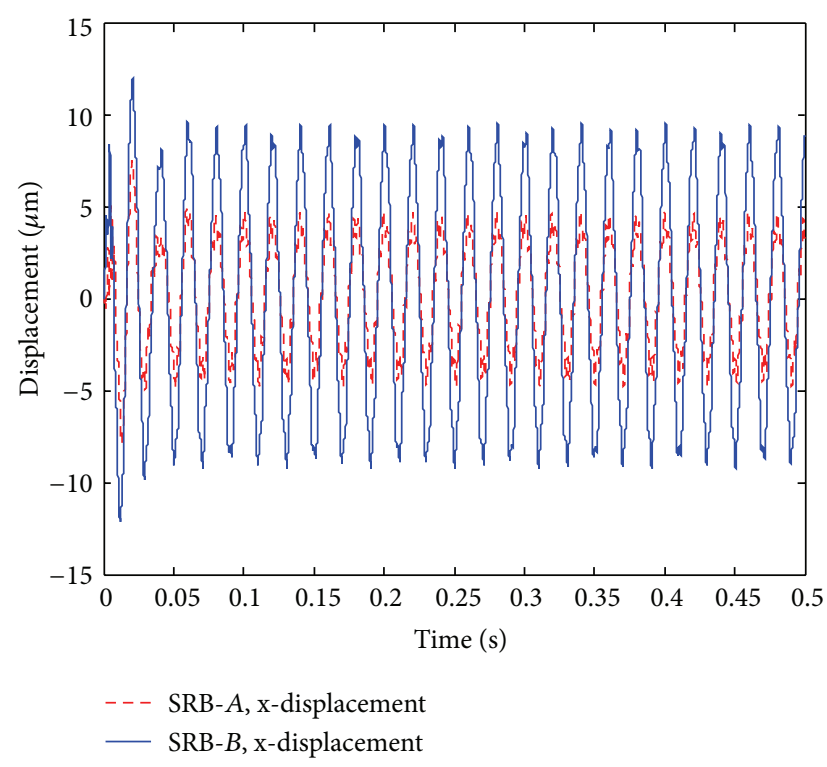

(a)

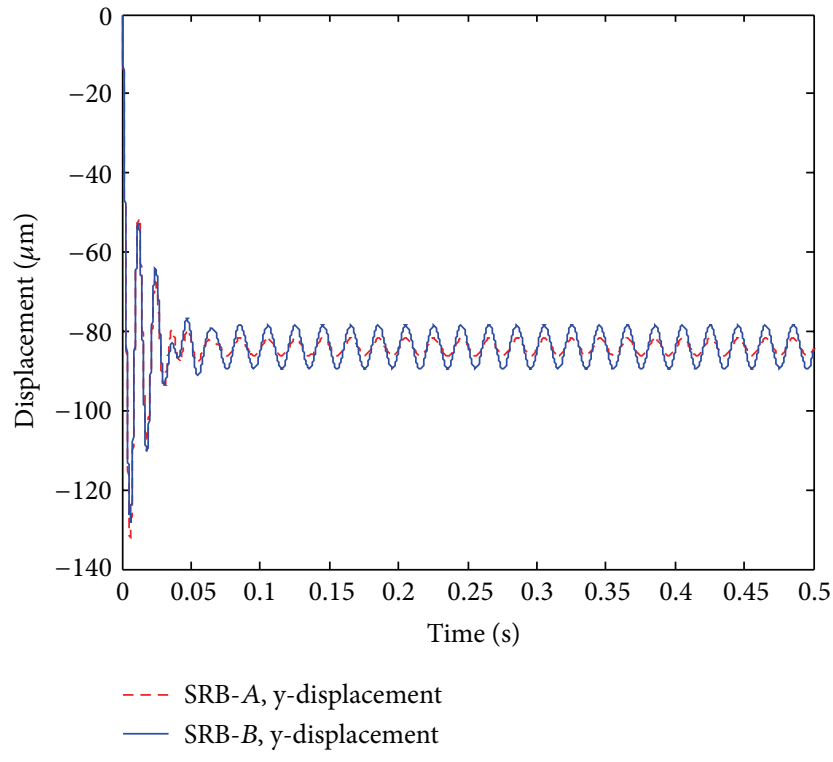

(b)

FIGURE 13: Simulated horizontal and vertical displacements of the rotor.

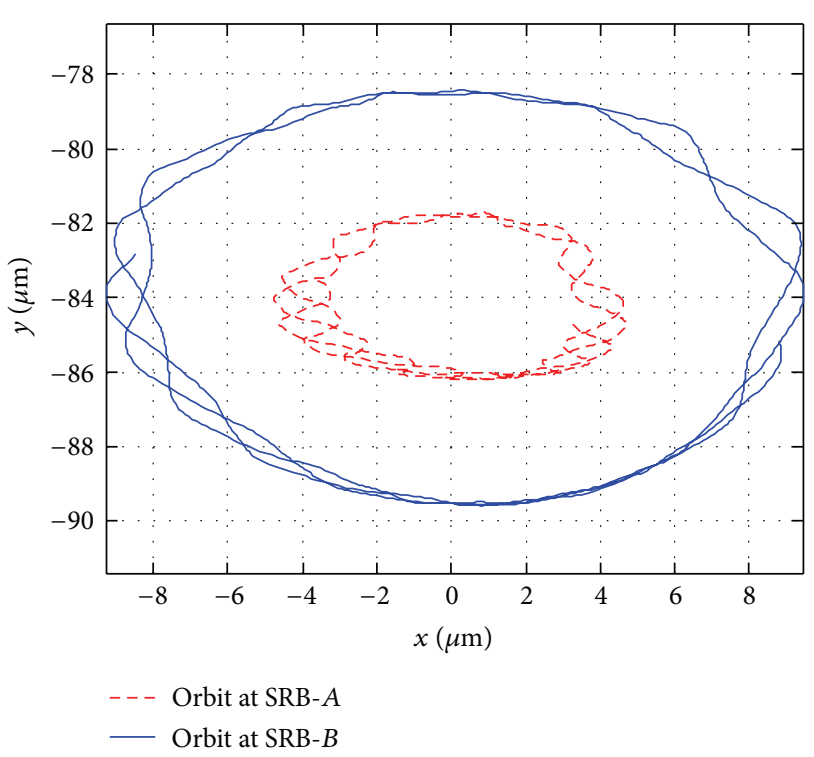

FIgURE 14: Rotor axis orbits at SRB $A$ and $B$ locations.

(v) SRB load carrying capacity increases with its number of rolling elements.

(vi) Even an ideal spherical roller bearing experiences varying compliance $(\mathrm{VC})$ vibration with a frequency equal to the roller-pass-outer-ring frequency of the bearing. However, the VC effect can be reduced with an angular offset of the side-by-side roller arrays. An $11.25^{\circ}$ angular shift seems to reduce the VC effect significantly.

To demonstrate the application of the newly developed SRB model in a typical real world analysis, a numerical simulation was carried out of a full rotor-bearing system comprising a rigid rotor supported by SRBs on either end of the rotor axle. The governing differential equations of motion for this specific rigid rotor-SRB system were solved numerically. The predicted bearing displacements are consistent with the general theory of rotor dynamics.

After a brief initial transient vibration, the rotor settles into steady-state harmonic vibration as a result of unbalanced forces. The rotor axis deflects in an elliptical orbit. Because of the positioning of the unbalanced load, the deflections for SRB $A$ are greater than those for SRB B. Elastic compression of the SRB structure seems to be only a few micrometers. However, the elliptical orbit of rotor axis displacement shows greater displacement in the $x$-axis direction than in the $y$-axis direction. This difference is the result of bearing clearance, which is taken up in the $y$-axis as the $y$-direction radial load acts on the bearing and not taken up in the $x$-axis direction.

This work can be extended in the future to include consideration of the SRB misalignment specification. Distributed and local defects, such as the waviness of the race surfaces or local defects in the inner and outer races, can be included as nonidealities. Furthermore, lubrication effects can be taken into account, especially for high operating speeds or high loads.

\section{References}

[1] T. A. Harris, Rolling Bearing Analysis, John Wiley \& Sons, New York, NY, USA, 2001.

[2] P. K. Goenka and J. F. Booker, "Spherical bearings: static and dynamic analysis via the finite element method," Journal of Lubrication Technology, vol. 102, no. 3, pp. 308-319, 1980.

[3] R. J. Kleckner and J. Pirvics, "Spherical roller bearing analysis," Journal of Lubrication Technology, vol. 104, no. 1, pp. 99-108, 1982. 
[4] S. Creju, I. Bercea, and N. Mitu, "A dynamic analysis of tapered roller bearing under fully flooded conditions part 1: theoretical formulation," Wear, vol. 188, no. 1-2, pp. 1-10, 1995.

[5] S. Creju, I. Bercea, and N. Mitu, "A dynamic analysis of tapered roller bearing under fully flooded conditions part 2: results," Wear, vol. 188, no. 1-2, pp. 11-18, 1995.

[6] H. Krzemiński-Freda and B. Warda, "Correction of the roller generators in spherical roller bearings," Wear, vol. 192, no. 1-2, pp. 29-39, 1996.

[7] U. Olofsson and S. Björklund, "3-D surface analysis of worn spherical roller thrust bearings," International Journal of Machine Tools and Manufacture, vol. 38, no. 5-6, pp. 485-493, 1998.

[8] T. J. Royston and I. Basdogan, "Vibration transmission through self-aligning (spherical) rolling element bearings: theory and experiment," Journal of Sound and Vibration, vol. 215, no. 5, pp. 997-1014, 1998.

[9] U. Olofsson, S. Andersson, and S. Björklund, "Simulation of mild wear in boundary lubricated spherical roller thrust bearings," Wear, vol. 241, no. 2, pp. 180-185, 2000.

[10] I. Bercea, D. Nélias, and G. Cavallaro, "A unified and simplified treatment of the non-linear equilibrium problem of double-row rolling bearings-part 1: rolling bearing model," Proceedings of the Institution of Mechanical Engineers J, vol. 217, no. 3, pp. 205212, 2003

[11] M. Cao, "A refined double-row spherical roller bearing model and its application in performance assessment of moving race shaft misalignments," Journal of Vibration and Control, vol. 13, no. 8, pp. 1145-1168, 2007.

[12] M. Cao and J. Xiao, "A comprehensive dynamic model of double-row spherical roller bearing-model development and case studies on surface defects, preloads, and radial clearance," Mechanical Systems and Signal Processing, vol. 22, no. 2, pp. 467489, 2008.

[13] M. T. van Zoelen, C. H. Venner, and P. M. Lugt, "The prediction of contact pressure-induced film thickness decay in starved lubricated rolling bearings," Tribology Transactions, vol. 53, no. 6, pp. 831-841, 2010.

[14] S. P. Harsha and P. K. Kankar, "Stability analysis of a rotor bearing system due to surface waviness and number of balls," International Journal of Mechanical Sciences, vol. 46, no. 7, pp. 1057-1081, 2004.

[15] S. P. Harsha, K. Sandeep, and R. Prakash, "Non-linear dynamic behaviors of rolling element bearings due to surface waviness," Journal of Sound and Vibration, vol. 272, no. 3-5, pp. 557-580, 2004.

[16] J. Sopanen and A. Mikkola, "Dynamic model of a deep-groove ball bearing including localized and distributed defects-part 1 : theory," Proceedings of the Institution of Mechanical Engineers K, vol. 217, no. 3, pp. 201-211, 2003.

[17] J. Sopanen and A. Mikkola, "Dynamic model of a deep-groove ball bearing including localized and distributed defects-part 2: implementation and results," Proceedings of the Institution of Mechanical Engineers K, vol. 217, no. 3, pp. 213-223, 2003.

[18] E. P. Gargiulo Jr., "A simple way to estimate bearing stiffness," Machine Design, vol. 52, no. 17, pp. 107-110, 1980.

[19] B. J. Hamrock and D. Dowson, "Isothermal elastohydrodynamic lubrication of point contacts-part I: theoretical formulation," Journal of Lubrication Technology, vol. 98, no. 2, pp. 223-229, 1976.

[20] D. E. Brewe and B. J. Hamrock, "Simplified solution for elliptical-contact deformation between two elastic solids," Journal of Lubrication Technology, vol. 99, no. 4, pp. 485-487, 1977.
[21] B. J. Hamrock, Fundamentals of Fluid Film Lubrication, McGraw-Hill, New York, NY, USA, 1994. 

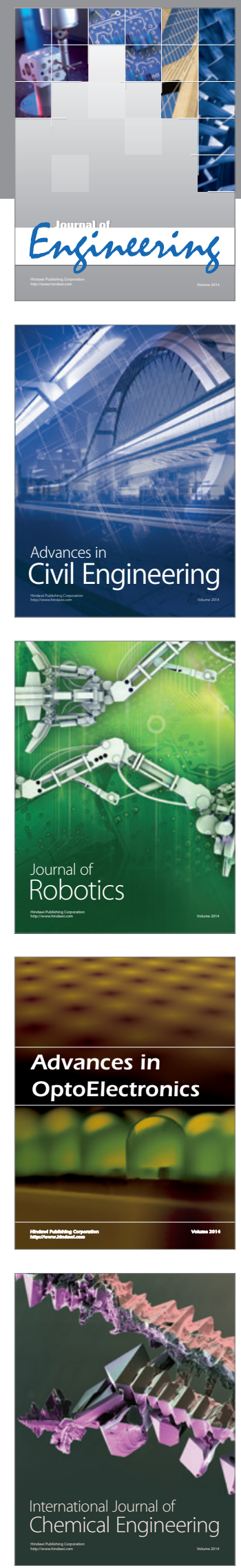

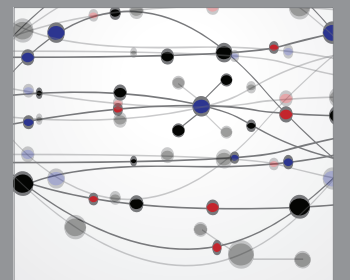

The Scientific World Journal
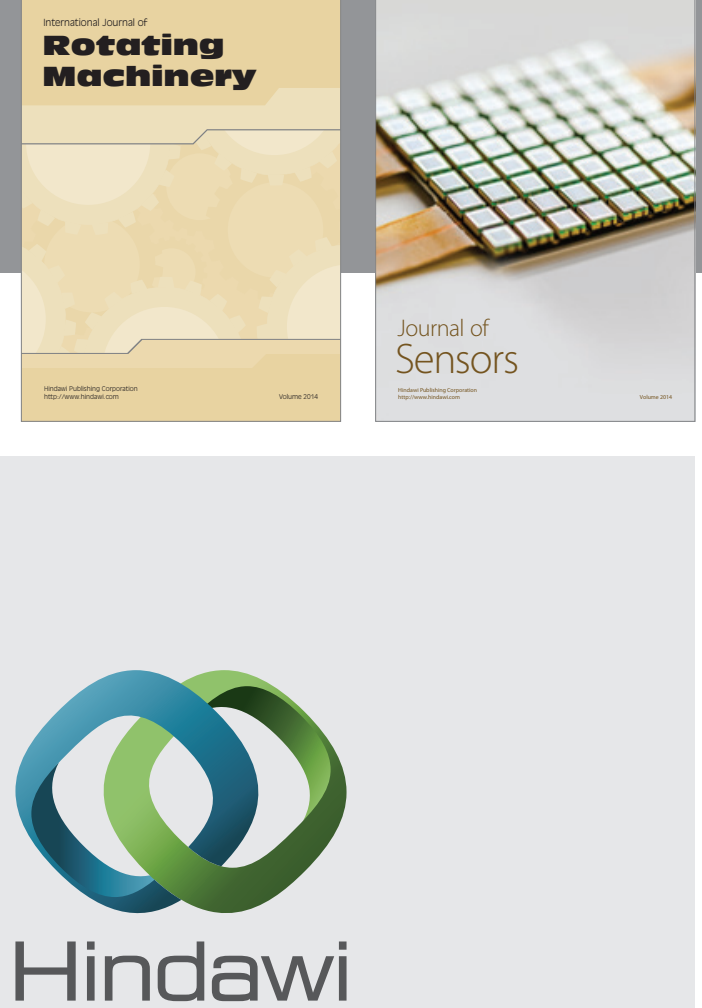

Submit your manuscripts at http://www.hindawi.com
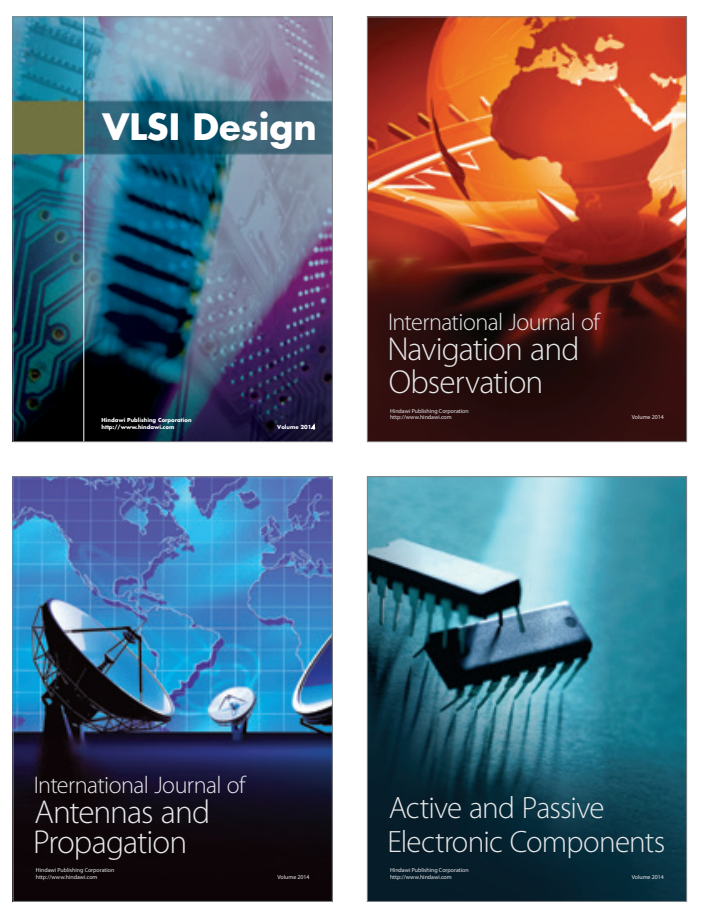
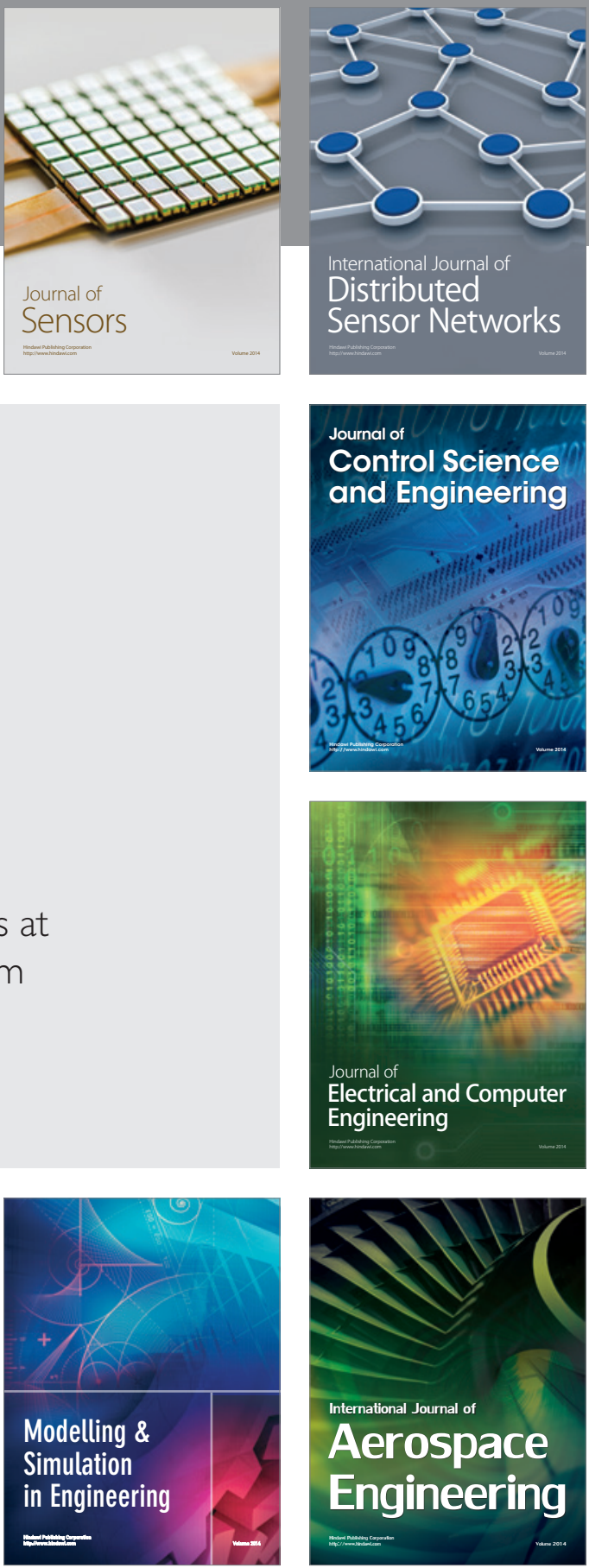

Journal of

Control Science

and Engineering
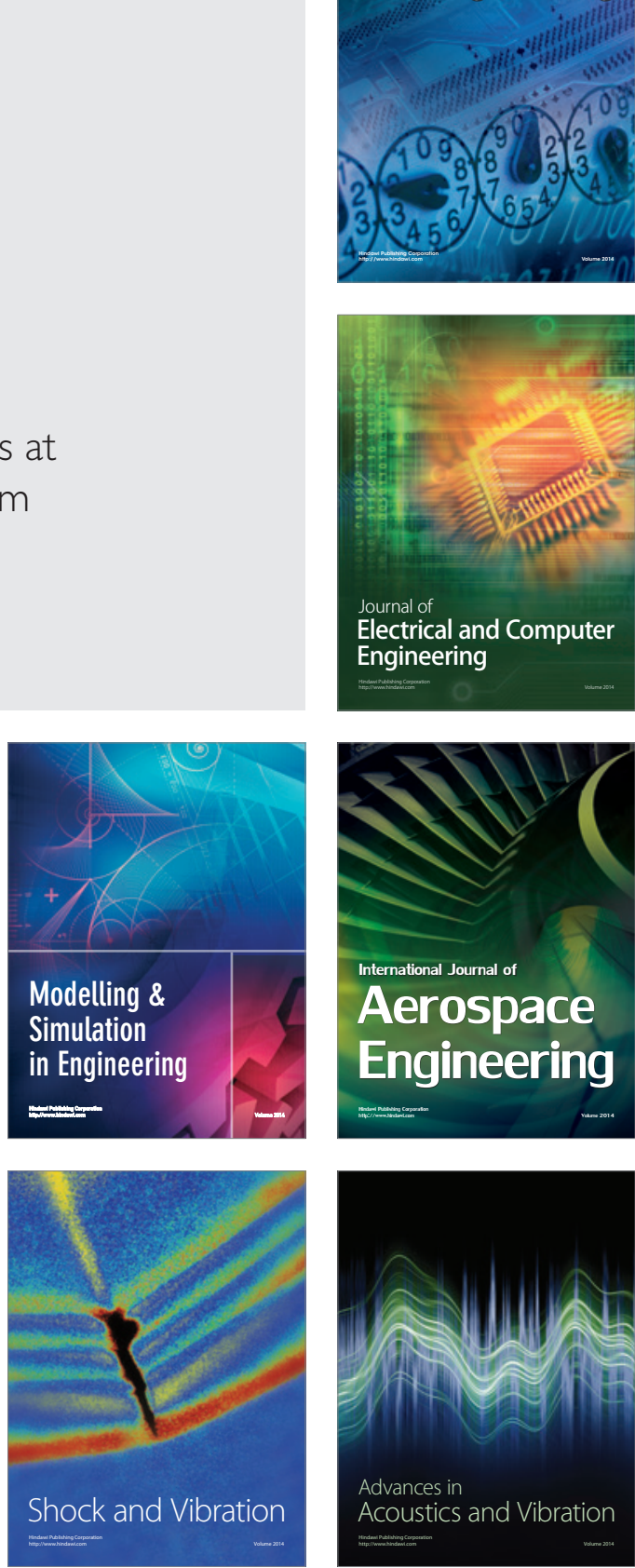